\title{
Correction to: Controlled modification of Nafion membrane with cationic surfactant
}

\author{
Julia A. Zakharova ${ }^{1}$ • Olga A. Novoskoltseva ${ }^{1}$ - Olga A. Pyshkina ${ }^{1} \cdot$ Evgeny A. Karpushkin $^{1} \cdot$ Vladimir G. Sergeyev $^{1}$ \\ (C) Springer-Verlag GmbH Germany, part of Springer Nature 2018
}

\section{Correction to: Colloid Polym Sci \\ https://doi.org/10.1007/s00396-018-4279-x}

The author noticed that the published paper contained error. Unfortunately, Eq. 1 in page 5 is missing even though the author noted a comment about the equation missing when submitting the proofs. Given in this paper is the missing equation.

\section{Nafion-SO ${ }_{3}{ }^{-} \mathrm{H}^{+}+\mathrm{DP}^{+} \mathrm{Cl}^{-} \rightleftharpoons$ Nafion- $\mathrm{SO}_{3}{ }^{-} \mathrm{DP}^{+}+\mathrm{HCl}$}

The original article has been corrected.

The online version of the original article can be found at https://doi.org/ $10.1007 / \mathrm{s} 00396-018-4279-\mathrm{x}$

Evgeny A. Karpushkin

eukarr@gmail.com

1 Chemistry Department, Lomonosov Moscow State University, Moscow, Russia 119992 